\title{
A Percepção dos professores de uma escola municipal de Boa Vista- Roraima, sobre a utilização dos espaços não formais de ensino na educação infantil
}

\author{
Rosana Cléia de Carvalho Chaves*, Arthur Philiphe Candido de Magalhães, \\ Henrique César Lopes, Ricardo Daniell Prestes Jacaúna, Ivanise Maria Rizzatti
}

Universidade Estadual de Roraima (UERR). Rua Sete de Setembro 231, Canarinho CEP 69306-530C, Boa Vista, RR, Brasil. Programa de Pós-graduação em Ensino de Ciências e Matemática (PPGEC)/Universidade Estadual de Roraima (UERR). *Email: rosanacleia@gmail.com

Recebido em : 11 de dezembro de 2015. Aceito em: 29 de agosto de 2016. Publicado PDF em: 31 de agosto de 2016

\section{RESUMO}

A percepção dos professores de uma escola municipal de Boa Vista- Roriama, sobre a utilização dos espaços não formais de ensino na educação infantil. Este artigo tem como objetivo analisar a percepção dos professores de uma Escola Municipal de Boa Vista/RR, sobre Espaços não Formais e as concepções vinculadas com o Ensino de Ciências na Educação Infantil. A pesquisa em questão apresenta uma abordagem qualitativa, envolvendo pesquisa participante, bibliográfica e de campo. Para tanto foram aplicados questionários a oito professoras da educação infantil buscando identificar a compreensão e percepção destes professores sobre a utilização dos espaços não formais e sua relação com o processo de ensino e aprendizagem. Os professores compreendem a importância da exploração de atividades em ambientes diferenciados da sala de aula, inclusive praças e parques, porém apenas quatro professoras relataram já ter utilizado diferentes espaços educativos, para o desenvolvimento de atividades com seus alunos. Assim, diante de tais questões há a necessidade de se rediscutir e executar atividades pedagógicas dentro de uma perspectiva inovadora, desafiadora e significativa promovendo a vinculação do ensino de ciências à alfabetização científica. Portanto, faz necessário pensar na formação do professor, uma vez que este profissional necessita estar fundamentado em metodologias, que possibilitem e oportunizem a aproximação e a interação entre o ensino e a aprendizagem.

PALAVRAS-CHAVE: Percepção Docente, Ensino de Ciências, Educação Infantil, Espaço não Formais.

\begin{abstract}
The perception of teachers of a Municipal School of Boa Vista, Roraima State, about the use of non-formal educational spaces in kindergarten. This article aims to analyze the perception of teachers of a Municipal School of Boa Vista in Roraima State, on non-Formal spaces and concepts related to science education in kindergarten. The research in question presents a qualitative approach, involving participatory research, bibliographic and field work. The questionnaires were applied to eight teachers of early childhood education seeking to identify the understanding and perception of teachers on the use of non-formal spaces and their relationship to the process of teaching and learning. The questionnaire analysis was realized that teachers understand the importance of exploration activities in different environments of the classroom, including squares and parks. Only four teachers reported having used different educational spaces for the development of activities with their students. Thus, there is a need to revisit and perform educational activities within an innovative, challenging and meaningful perspective promoting the linkage of scientific literacy science teaching. Therefore, is necessary to think of the teacher training, since this professional needs to be based on methodologies that allow and encourage approach and the interaction between teaching and learning.
\end{abstract}

KEY WORDS: Perception Lecturer, Science Education, Early Childhood Education, not Formal Space. 


\section{INTRODUÇÃO}

Desde muito cedo as crianças são questionadoras sobre o mundo e os fenômenos decorrentes a sua volta, dessa forma, manifestam questionamentos e curiosidades que aos poucos vão sendo compreendidos e partilhados com as pessoas que as rodeiam.

Neste aspecto, a criança é alguém que aprende pela interação com o outro, pelo toque, pela busca e pela curiosidade. Craidy \& Kaercher (2001) apontam que a criança, para construir conhecimentos, precisa agir, perguntar, ler o mundo, olhar imagens, criar relações, testar hipóteses e refletir sobre o que faz, de modo a reestruturar o pensamento permanentemente.

Partindo do entendimento que a aprendizagem decorre de um processo contínuo e integrado a vivência e experiências do indivíduo, percebe-se então que a educação infantil é uma etapa muito importante para a formação intelectual do indivíduo, por ser o princípio de desenvolvimento das experiências, aprendizagens e escolarização. Sendo assim, nessa fase são construídos os primeiros pilares de sustentação ao alicerce da vida do estudante e da formação do indivíduo.

É neste contexto que as relações sociais favorecem elementos essenciais para a socialização. Esse processo de socialização e de experiências constitui-se em combinação de informações advindas do meio descoberto espontaneamente pela criança, resultando uma interação na qual o sujeito é sempre ativo e dinâmico, que a todo o momento interage com a realidade operando ativamente, aprendendo e construindo seu próprio conhecimento.

Todo sujeito tem a sua maneira própria de aprendizagem e os meios de construir o conhecimento, esse processo inicia-se desde o nascimento e constitui-se em molde ou esquema, sendo fruto do inconsciente simbólico. Assim, as mudanças que acontecem no comportamento da pessoa são resultados do vínculo entre as experiências anteriores e os novos conhecimentos adquiridos. Fernandes (2001, p. 43)

Corroborando com este pensamento Giovanni (2000, p.93) ainda diz que "é fundamental que se considere a aprendizagem um processo do aluno, e as ações que se sucedem devem necessariamente ser dirigidas à construção do conhecimento por esse sujeito ativo".

Nesta perspectiva, os espaços não formais se apresentam como oportunidades de aprendizagens, uma vez que possibilitam a aproximação da criança com a natureza, oportunizam a observação, instigam a investigação, proporcionam o desenvolvimento da curiosidade, tanto de alunos quanto de professores.

Rocha \& Fachín-Terán (2010) afirmam que os espaços não formais são imprescindíveis para ensinar e aprender ciências, contribuindo para a aproximação dos estudantes com o ambiente natural e para uma compreensão maior sobre os conteúdos de Ciência. Acrescentam ainda que esses espaços complementam as atividades pedagógicas da escola no Ensino de Ciências, "viabilizando um conjunto de informações que pode beneficiar não apenas o conhecimento dos estudantes, mas também para o exercício da cidadania" (Rocha \& Fachín-Terán 2010).

Pensar nesta possibilidade de educação é permitir à criança amplas possibilidades de compreensão, de novas vivências para a construção de novos conceitos, na aquisição de experiências, de descobertas e novos rumos a novas aprendizagens, assim como também de intervenção e transformação da sua realidade.

Neste processo, os diferentes espaços educativos desempenham uma função importante possibilitando ampliações quanto à educação científica. Partindo desse entendimento, percebe-se que as aulas realizadas fora da instituição escolar também merecem destaque, por apresentar peculiaridades específicas e diferenciadas da sala de aula, em se tratando da dinâmica de espaços, estruturas e realidades distintas.

A este respeito, a educação no espaço não formal possibilita ao estudante um envolvimento em experenciar momentos em ambientes diferentes, que contribuem para desvelar e evidenciar os conteúdos de ciências ao cotidiano dos indivíduos. Para Krasilchik \& Marandino (2004) "os espaços não formais possibilitam aos estudantes um ambiente prazeroso de aprender e fazer ciência".

Neste contexto, compreende-se que a educação não formal caracteriza-se por um conjunto de ações e processos específicos que 
advêm de espaços próprios, que tem como função a formação ou a instrução de indivíduos. O conceito dessa proposta e os fatores que promovem seu fortalecimento são discutidos e defendidos por vários autores (Krasilchik \& Marandino 2004; Ghanem 2008; Gohn 2010; Rocha \& Fachín-Terán 2010).

Pensar nesta forma de educação é refletir em um processo de inserção do indivíduo na sociedade, assim como também na possibilidade de intervir e transformar a sua realidade. Neste processo, o espaço desempenha uma função importante possibilitando ampliações quanto ao conhecimento científico.

Partindo desse entendimento, acredita-se que as aulas realizadas fora da instituição de ensino formal, pode favorecer uma maior interação entre os estudantes, assim como também, ajustar o aprendizado em consonância das informações e à contextualização dos conteúdos curriculares, dessa forma poderá conduzir ao desenvolvimento e possibilidades de promover uma prática pedagógica em diferentes espaços educativos.

Neste aspecto, a escola necessita evidenciá-las em seu contexto, como nos diz Haetinger (2005, p. 70), "se a escola continuar não interagindo o ensino com a vida prática dos alunos, está correndo o risco de ficar falando sozinho, na sala de aula".

Haetinger $(2005$, p.71) ainda acrescenta que:

Em nosso trabalho de educadores devemos sempre oportunizar aos alunos o acesso à informação e a construção de conhecimentos coletivos. Ao oferecermos este tipo de vivência, buscamos a motivação do aluno e o comprometimento do mesmo com a aprendizagem individual e do grupo ao qual ele pertence.

Neste sentido, para promover o ensino em espaços não formais na educação infantil, é necessário pensar na formação do professor, uma vez que estes precisam ter conhecimentos e compreensão quanto a especificidades desta fase. Em suma, percebe-se que os educadores precisam conhecer, compreender, operacionalizar atividades escolares em diferentes espaços escolares de forma a complementar e a enriquecer a dinâmica do processo de ensino e de aprendizagem dos indivíduos.

Diante do exposto, este trabalho tem como objetivo analisar a percepção dos Professores de uma Escola Municipal de Boa Vista- Roraima, acerca das concepções sobre Espaços não Formais e sua relação com o Ensino de Ciências na Educação Infantil, tendo como parâmetro evidências a partir da aplicação e análise de questionários, segundo a compreensão e percepção de oito professoras sobre a temática em questão.

Neste sentido, busca-se compreender qual a compreensão desses profissionais referente aos Espaços não Formais e sua aplicabilidade no contexto de sala de aula da respectiva escola.

\section{MATERIAL E MÉTODOS}

A trajetória metodológica desta pesquisa configurou-se na seleção do grupo de 08 professoras atuantes na educação infantil em uma escola da rede pública do Município de Boa Vista, Roraima, que responderam a um questionário contendo 17 questões, sendo 03 questões abertas, 05 questões fechadas e 09 questões mistas (abertas e fechadas). Este questionário teve como propósito traçar o perfil destes professores e identificar sua percepção frente ao espaço não formal de ensino, na perspectiva de ampliar possibilidades de promover a alfabetização científica sobre o tema meio ambiente com estudantes da educação infantil. Partindo dessa compreensão, buscaram-se evidências na realidade local da referida escola pautada no entendimento entre a prática escolar e a temática em questão.

Neste ponto, Gil (2002, p. 17) define "pesquisa como um procedimento racional e sistemático que tem como objetivo, proporcionar respostas aos problemas, que são propostos".

Quanto aos objetivos, trata de uma pesquisa exploratória com abordagem qualitativa. Neste aspecto, tais abordagens presentes nesta pesquisa se configuram por aferir informações e buscar mensurar uma realidade específica local, neste caso a partir da análise dos questionários e interpretações evidenciadas nesta pesquisa.

Em suma, o instrumento utilizado na 
realização da pesquisa, para a mensuração das informações e o aprofundamento de uma realidade específica local apresenta-se como elemento de validação e fundamentação da pesquisa.

Portanto, tais evidências buscam relacionar práticas pedagógicas e a utilização de diferentes espaços educativos para promoção da alfabetização científica aos estudantes de ensino infantil expressas na concepção de oito professoras do Ensino Infantil em uma Escola Municipal de Boa Vista/RR.

\section{RESULTADOS E DISCUSSÃO}

Todas as oito professoras atuantes na educação responderam ao questionário, explicitando sua percepção quanto às possibilidades de aprendizagem frente ao espaço não formal de ensino. Buscou-se também identificar o perfil profissional e as respostas estão apresentadas na tabela 1.

$\mathrm{O}$ perfil profissional das professoras entrevistadas é importante, uma vez que facilita a compreensão e análise dos dados, sendo imprescindível compreender a significação da realidade expressa nos fatos mediante o uso dos métodos necessários para essa execução. Em relação ao, os dados obtidos sobre o tempo de atuação na educação básica, na educação infantil e na escola estão apresentados nas figuras 1,2 e 3, respectivamente.

Segundo os dados analisados, observamos que as professoras atuam na educação básica entre 01 a 21 anos, no ensino infantil entre 01 a 10 anos, e estão na escola entre 01 a 05 anos. Vale ressaltar que mensurar as informações é buscar o aprofundamento dessa percepção e da realidade local, a fim de avaliar tais evidências. Quanto a questões específicas que tratam da definição de espaço não formal, foi notório perceber que as professoras destacaram que espaço não formal compreende diferentes locais da escola, onde é possível desenvolver atividades educativas, ou seja, são espaços simples, onde a aprendizagem acontece mesmo não sendo direcionada.

Corroborando com este pensamento, Jacobucci (2008) descreve que esses espaços [...] passam a exercer uma função social que deve ser desempenhada com a máxima responsabilidade, isto que é uma decisão política que implica a formação de um outro indivíduo, que pelas características de seu trabalho também tem uma função social de formar outros indivíduos cidadãos deste país.

As professoras destacaram como positiva a utilização de práticas educativas em espaço não formal na educação infantil, porém quando questionadas sobre a prática da utilização desses diferentes espaços, quatro professoras informaram que nunca desenvolveram atividades utilizando espaço no formal. As demais professoras afirmam que desenvolveram atividades com seus alunos no pátio e outras áreas externas da escola, além de passeios no Zoológico, explorando diversas

Tabela 1. Perfil dos professores atuantes na Educação Infantil de uma Escola Municipal localizada na Zona Oeste de Boa Vista, Roraima.

\begin{tabular}{|l|l|l|l|l|}
\hline Participante & Idade & Formação & $\begin{array}{l}\text { Ano de } \\
\text { Conclusão }\end{array}$ & Pós Graduação \\
\hline P1 & 38 & $\begin{array}{l}\text { Pedagogia e } \\
\text { História }\end{array}$ & 2010 & Não possui \\
\hline P2 & 43 & Pedagogia & 2009 & Psicopedagogia institucional \\
\hline P3 & 34 & Pedagogia & Não declarou & $\begin{array}{l}\text { LIBRAS - Lingua Brasileira } \\
\text { de Sinais }\end{array}$ \\
\hline P4 & 41 & Pedagogia & 2002 & Gestão Escolar \\
\hline P5 & 38 & Pedagogia & 2008 & Gestão Escolar \\
\hline P6 & 31 & Pedagogia & 2011 & $\begin{array}{l}\text { Educação no Campo e suas } \\
\text { Metodologias de Ensino }\end{array}$ \\
\hline P7 & 48 & Pedagogia & 2007 & Não possui \\
\hline P8 & 33 & Pedagogia & 2006 & Literatura e Ensino \\
\hline
\end{tabular}


temáticas como: meio ambiente e natureza, reciclagem de papel, animais, lateralidade entre outras temáticas na disciplina de Ciência. Estas últimas ainda destacaram como pontos positivos: interesse, motivação, entrosamento, alegria, a boa vontade dos alunos em associar conceitos e a compreender conteúdos, sendo assim demonstraram disposição para executar atividades em aulas práticas. Dentre os pontos negativos, as professoras enfatizaram: a

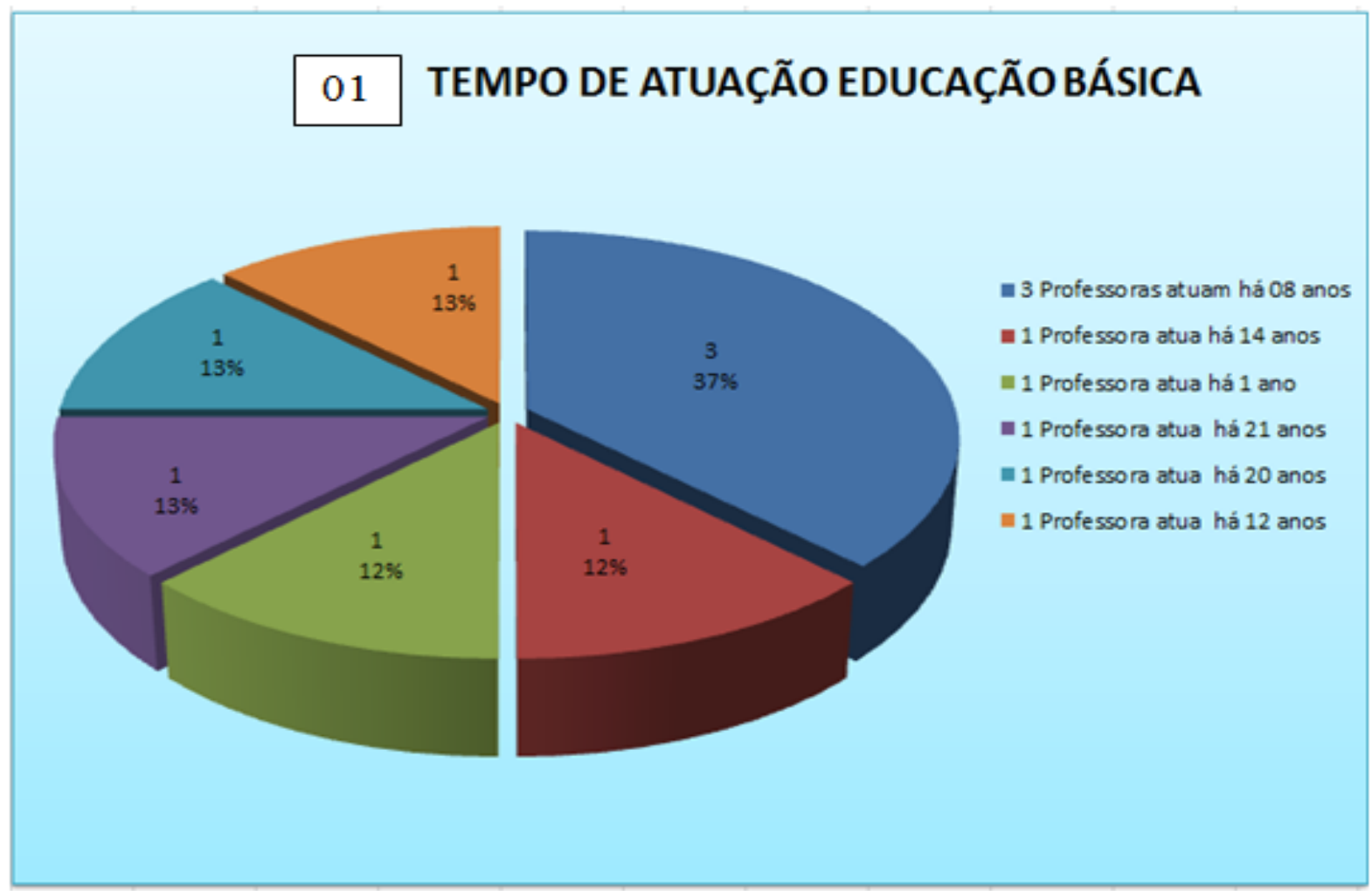

Figura 1. Tempo de atuação Educação Básica das professoras de uma escola municipal de Boa Vista, Roraima.

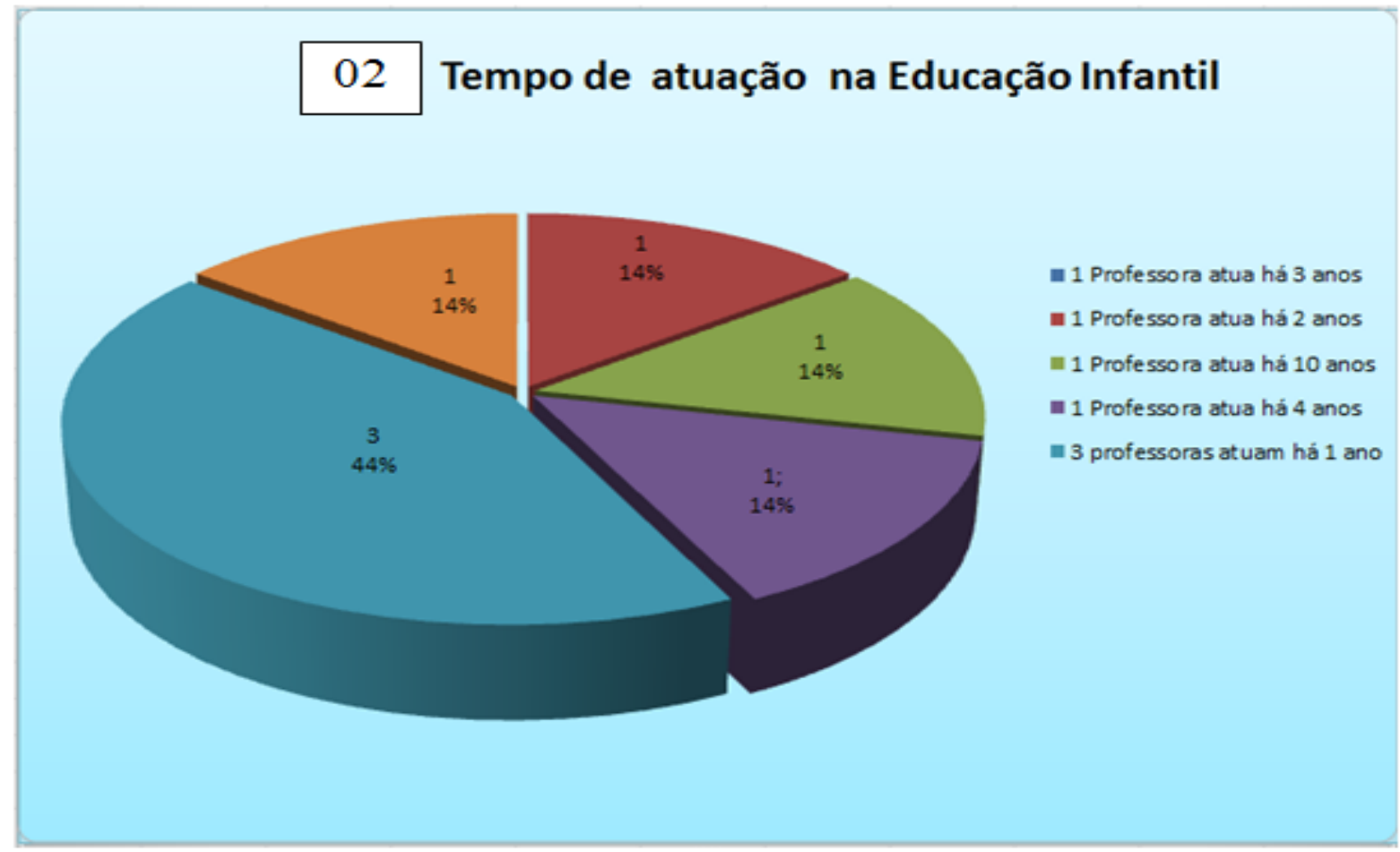

Figura 2. Tempo de atuação Educação Infantil das professoras de uma Escola municipal de Boa Vista, Roraima. 


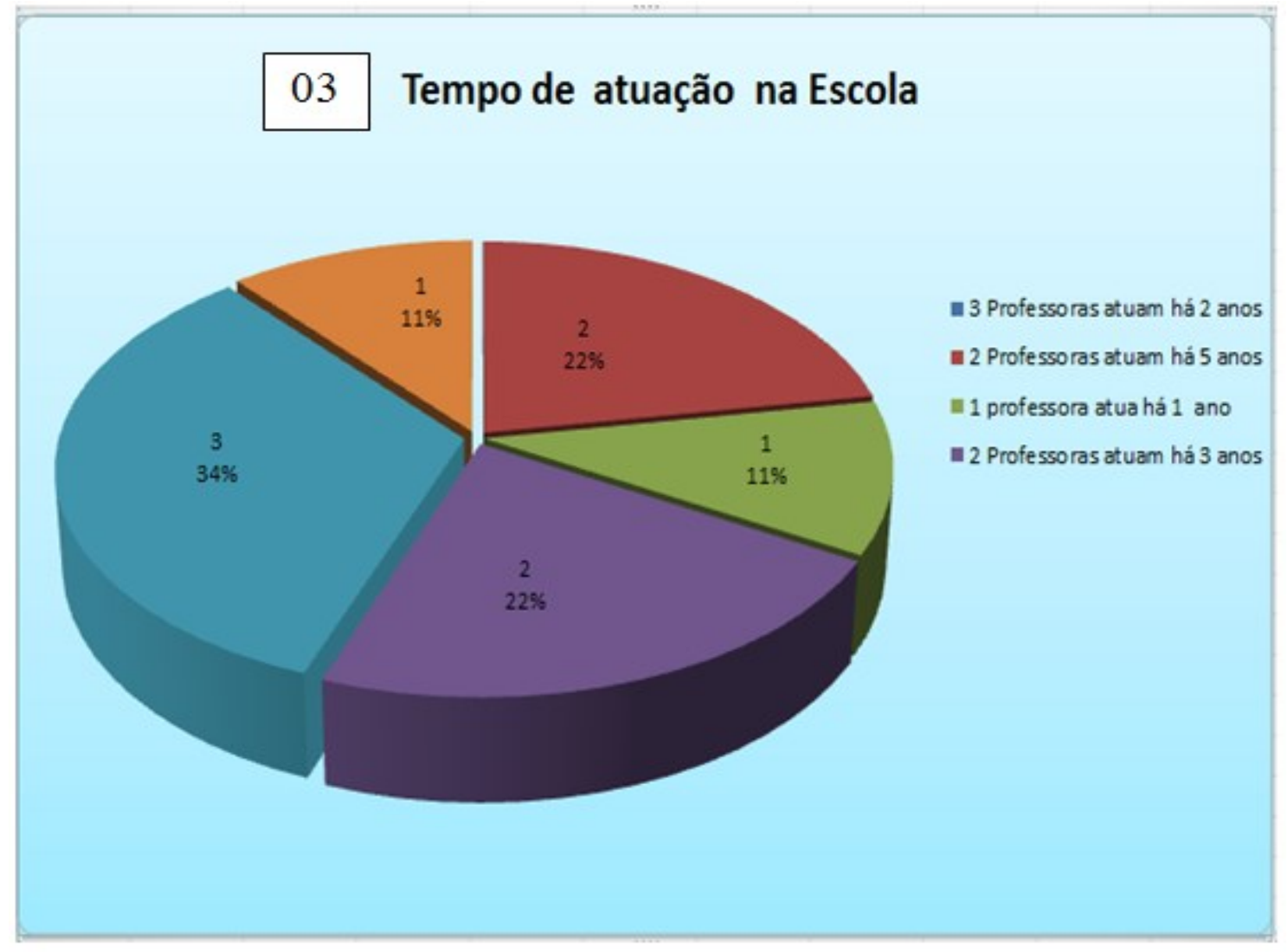

Figura 3. Tempo de atuação das professoras na escola municipal de Boa Vista, Roraima.

dispersão dos alunos por alguns momentos, porém acrescentaram que, um bom direcionamento evita esse tipo de comportamento, pelo fato que esses espaços proporcionam liberdade em executar diferentes atividades escolares na exploração e aproximação de outros contextos.

Quando questionadas sobre o potencial de uma praça que se localiza ao lado da escola enquanto espaço não formal de ensino, todas as professoras foram unânimes em afirmar que é um espaço que possibilita aproximação e contato com a natureza e com o meio ambiente, a recreação, a ampliação de vivências e socialização e a ascensão do ensino de ciências.

Nesta perspectiva, as professoras já observaram a utilização desse espaço por alguns professores da escola. No entanto, tais atividades eram voltadas basicamente ao entretenimento e à exploração de outras atividades, como por exemplo, em algumas aulas de ciências com conteúdos específicos como clima, plantas, tipos de paisagem, ambiente e sua conservação, dentre outras.

No que se refere à realização de ações da escola na praça, seis professoras disseram raramente utilizar esse espaço e tinham uma tímida participação de ações escolares nesse espaço. No entanto, duas professoras afirmaram participar ativamente na utilização desse espaço pela escola, como na realização de eventos e desenvolvimento de projetos. Estes momentos aconteciam porque a escola tinha como meta promover a socialização dos alunos e a participação da comunidade escolar em atividades como "caminhada: meio ambiente", semana do trânsito e dia das crianças. Estas professoras afirmaram que acreditam na importância da exploração de atividades em ambiente diferenciados da sala de aula, inclusive na praça e que essas atividades são iniciativas para a introdução e dinâmica de aulas diferenciadas em diferentes espaços educativos para trabalhar diferentes assuntos. Dentre estes assuntos foram citados: meio ambiente, sociedade e natureza, estudo das plantas, cuidado, limpeza, higiene e conservação ambiental. Ainda nestes locais, as professoras ainda mencionaram a possibilidade de trabalhar os pontos turísticos, passeio no zoológico, piquenique, brincadeiras dirigidas, momentos de socialização, entretenimento, recreação, observação para 
registro em sala no quesito meio ambiente, campeonatos, entre outras atividades.

Segundo as professoras, a escola desenvolve projetos que estimulam a prática pedagógica na utilização em espaço não formal, por meio de oficinas e capacitação no horário oposto, mediante desenvolvimento de projetos voltados para a temática meio ambiente e passeios no zoológico, em pontos turísticos, no cinema, entre outros. Neste sentido, a coordenação pedagógica desenvolve atividades e momentos de estudo com os professores voltados a diversas temáticas, entre elas: planejamento, processo de ensino aprendizagem, dificuldades de aprendizagem, adaptação de atividades para crianças com necessidades educacionais.

Ressalta-se que a escola possui a prática de desenvolvimento de eventos e palestras sobre temáticas pertinentes ao contexto educativo, envolvendo toda a escola e a comunidade para momentos de estudos que privilegiam a reflexão sobre a relação de desafios no processo de ensino e aprendizagem, proporcionando a socialização de experiências de sala aula, mediante exploração de projetos de diversos projetos como "Educação especial", "Educação inclusiva", "Meio ambiente - preservar para crescer" e "Mais educação".

Além disso, sete professoras mostraram interesse em participar de oficinas sobre espaços não formais, para conhecer e discutir as perspectivas de aprendizagem em espaços educativos não formais no ensino de ciências.

Nesta perspectiva, para promover a educação em espaços não formais na educação infantil, é necessário pensar na formação do professor, uma vez que este precisa estar fundamentado em novas metodologias, para promover essa interação da educação em ciência na educação infantil.

\section{CONSIDERAÇÕES FINAIS}

A partir da análise dos questionamentos quanto aos diferentes olhares apresentados pelas professoras sobre questões que envolvem Espaços não Formais de ensino e a prática cotidiana, percebeu-se que os momentos de discussão e reflexão são de fundamental importância. De formar a garantir situações didáticas diferenciadas na prática educacional, de forma a culminar com a socialização de experiências de sala de aula e com a aprendizagem dos alunos.

A escolha da temática em questão surgiu a partir das inquietações observadas entre $o$ discurso e a prática dos professores da educação infantil, frente ao desenvolvimento de atividades que envolvem o ensino de ciências.

Dessa forma, ao abordar estas questões percebeu-se que, a prática da utilização em diferentes espaços merece ter seu lugar de destaque no processo prático da sala de aula, por aguçar e estimular cada vez mais a capacidade de inquirir, pesquisar e descobrir de maneira que os alunos aprendam e prove de outras experiências.

Diante das respostas das professoras percebemos que, todas acreditam na importância da exploração de atividades em ambientes diferenciados da sala de aula, inclusive em uma praça próxima a escola. Porém quando se trata de utilizar esse espaço, poucas professoras utilizam ou já utilizaram este espaço para desenvolvimento de atividades com seus alunos.

Em suma, as discussões de enfoque desta pesquisa possuem grande relevância para a comunidade escolar, por proporcionar reflexão e fomentar a prática pedagógica a partir da mediação em espaços não formais de ensino e por explorar esse espaço, que por muitas vezes encontra ocioso. Assim, as evidências pontuadas demonstram a necessidade de se rediscutir e repensar na execução de atividades pedagógicas numa perspectiva inovadora, desafiadora e significativa, integrando-as ao contexto da aprendizagem dos alunos.

\section{AGRADECIMENTOS}

A Universidade Estadual de Roraima e a equipe de Professores da Educação Infantil da Escola Municipal Campo que aceitaram participar da pesquisa.

\section{REFERÊNCIAS BIBLIOGRÁFICAS}

Appolinário, F. 2011. Dicionário de Metodologia Científica: um guia para produção do conhecimento científico. São Paulo: Atlas. 
Beuren, I. M. 2009. Como elaborar trabalhos monográficos em Contabilidade: teoria e prática. 3. Ed. São Paulo: Atlas.

Craidy, M.C. \& Kaercher, G.E.P. S. 2001. Educação Infantil, para que te quero? Porto Alegre: Artmed. p. 13 a 22.

Fernandes, M. A. S. 2001. Os segredos da alfabetização: prática para professores e pais. São Paulo: Ediouro Publicações.

Fonseca, V. 2002. Introdução Métodos de pesquisa. Porto Alegre: Artes Médicas.

Gil, A. C. 2002. Como elaborar projeto de pesquisa. 4. Ed. São Paulo: Atlas. 2010. Metodologia do Ensino Superior. 4. Ed. São Paulo: Atlas.

Giovanni, A. C. 2000. Ensino de geografia: Práticas e textualizações no cotidiano. Porto Alegre: Mediação. $86 \mathrm{p}$.

Gohn, M.G. 2010. Educação não formal e o educador social: atuação no desenvolvimento de projetos sociais. São Paulo: Cortez. $38 \mathrm{p}$.

Ghanem, E. 2008. Educação formal e não formal: pontos e contrapontos. São Paulo: Summus.

Haetinger, M. G. 2005. O Universo Criativo da Criança na educação. (www.maxcriar.com.br/) Acesso em: 19/09/2015.

Lakatos, E.M. \& Marconi, M.A. Fundamentos de metodologia científica. 7. Ed. São Paulo: Atlas, 2010.

Jacobucci, D.F.C. 2008. Contribuições dos espaços não formais de educação para a formação da cultura científica. Uberlândia, 302p.

Krasilchik, M.\& Marandino M. 2004. Ensino de ciências e cidadania. São Paulo: Moderna.

Marconi, M.A \& Lakatos, E. M. 2009. Fundamentos de Metodologia Cientifica. 6 Ed, São Paulo. Atlas.

Rocha, S. C. B. \& Fachín-Terán, A.F. 2010. O uso de Espaços não Formais como estratégia para o Ensino de Ciências. Manaus: UEA/Escola Normal Superior/ PPGEECA.

Trujillo, F. A. 1982. Metodologia da Pesquisa científica. São Paulo: McGraw-Hill do Brasil, 1982. 